\title{
Analisis Tingkat Pengetahuan, Sikap, dan Motivasi Peternak Sapi dalam Adopsi Teknologi Inseminasi Buatan di Sumbawa Barat
}

\author{
Muhyidin $^{1}$, Chairussyuhur Arman ${ }^{2 *}$, Lalu Ahmad Zaenuri \\ ${ }^{1}$ Program Studi Magister Manajemen Sumberdaya Peternakan Universitas Mataram \\ ${ }^{12}$ Fakultas Peternakan Universitas Mataram \\ Jl. Majapahit No. 62 Mataram Lombok Nusa Tenggara Barat 83125 \\ *Email korespondensi: chairussyuhur.arman@yahoo.com
}

(Diterima: 09-05-2019; disetujui 27-07-2019)

\begin{abstract}
ABSTRAK
Upaya pengembangbiakan sapi melalui penerapan inseminasi buatan (IB) dengan semen beku terbukti berhasil meningkatkan produktivitas sapi potong di Provinsi NTB. Namun tingkat adopsi teknologi IB oleh peternak sapi di Kabupaten Sumbawa Barat selama lebih dari 10 tahun masih rendah. Tujuan penelitian ini adalah untuk memperoleh hubungan antara pengetahuan, sikap dan motivasi peternak sapi dalam adopsi teknologi IB. Penelitian ini adalah deskriptif korelatif dengan metode wawancara tatap muka, rancangan cross sectional dengan bantuan kuesioner terstruktur dari 84 responden. Data yang diperoleh dianalisis menggunakan Spearman Rho. Hasil penelitian menunjukkan bahwa $90,5 \%$ responden mengetahui manfaat teknologi IB dan hanya $8,4 \%$ responden yang tidak mengetahui manfaat teknologi IB. Sebanyak $60-70 \%$ responden mengetahui faktor-faktor yang mempengaruhi keberhasilan IB dan tanda-tanda estrus yang diketahui dari keluarnya lendir dari vulva, warna merah vagina dan sapi menjadi gelisah. Sekitar $70 \%$ responden tidak memahami waktu yang tepat untuk inseminasi serta peralatan yang digunakan untuk IB. Semua responden setuju dengan program IB, namun, tidak ingin memiliki keterampilan dalam melakukan IB. Disimpulkan bahwa tingkat pengetahuan, sikap dan motivasi responden secara umum cukup baik dalam upaya untuk mengadopsi teknologi IB dan ada hubungan positip dan signifikan $(\mathrm{P}<0,05)$ antara pengetahuan, sikap dan motivasi.
\end{abstract}

Kata Kunci: adopsi, inseminasi buatan, peternak sapi, teknologi

\begin{abstract}
Improving cattle productivity in NTB by breeding using AI technology has been successful. In West Sumbawa District AI has been used for over 10 years, however, the level of its adoption is still low. The study was conducted to obtain the relationships between knowledge, attitude and motivation of cattle farmers in the adoption of AI technology. A survey approach was used in this study and a questionnaire was developed to gather the data. The sample size for cattle farmers was 84 . Data were analyzed using Spearman Rho. About ninety-five respondents apprehended the benefits of AI technology and only $8.4 \%$ did not know. Around $60-70 \%$ of respondents understood factors that affected the success of AI and recognized signs and characteristics of oestrus. About $70 \%$ of respondents did not understand the fixed time for insemination as well as the equipment used for AI. All respondents agreed with the AI program, however, they did not prefer to have skills in carrying out AI. In conclusion, the level of knowledge, attitude and motivation of respondents in general was quite good in the effort to adopt $\mathrm{AI}$ technology and there were positive and significant $(\mathrm{P}<0.05)$ relationships between knowledge, attitude, and motivations.
\end{abstract}

Keywords: adoption, artificial insemination, cattle farmers, technology 


\section{PENDAHULUAN}

Peternakan sapi potong di Indonesia umumnya merupakan usaha rakyat yang skalanya kecil, bersifat sampingan dan tradisional. Sistem pemeliharaan yang demikian mengakibatkan produktivitas sapi potong menjadi kurang optimal.Upaya mengoptimalkan produktivitas sapi potong tidak lepas dari berbagai macam tantangan, salah satunya adalah pengadaan bibit (Ma'sum et al., 1993). Pola pembibitan sapi potong bersifat lintas sektoral dan melibatkan berbagai aspek kepentingan sosial dan ekonomi di mana dalam batas-batas tertentu tidak dapat dikendalikan oleh unsur birokrasi. Pada prakteknya pola pembibitan sapi sangat dibatasi oleh tugas dan wewenang administratif daerah. Menyadari kekurangan tersebut maka berbagai langkah kebijakan telah ditempuh oleh pemerintah di antaranya melalui pemuliabiakan (breeding) ternak sapi dengan cara mengadopsi inovasi teknologi baruseperti teknologi inseminasi buatan (Pateda, 2010).

Inseminasi buatan (IB) sebagai teknologi reproduksi generasi pertama merupakan rangkaian proses yang berturutan mulai dari penampungan semen seekor pejantan unggul, pengenceran, pembekuan, penyimpanan sampai memasukkan semen secara artifisial dengan menggunakan peralatan inseminasi ke dalam saluran reproduksi seekor betina agar menghasilkan pembuahan (Shehu et al., 2010). Foote (2002) menyatakan bahwa teknologi IB dapat mendukung penyebaran secara maksimal sifat-sifat yang diinginkan dari seekor pejantan unggul pada sejumlah besar hewan betina. Proses ini menciptakan hasil yang tidak dapat dicapai melalui perkawinan alami. Teknologi IB dapat meminimalisir risiko penyebaran penyakit kelamin menular pada sapi karena prosedurnya meniadakan pelibatan kontak fisik antara sapi jantan dengan sapi betina. Selain itu, Eklundh (2013) mengemukakan bahwa dengan IB, ternak menjadi lebih sehat dan kemam-puannya untuk memproduksi anak juga meningkat sehingga meningkatkan status mata pencaharian di antara peternak sapi.

Akan tetapi, keberhasilan pengembangan dan penerapan suatu teknologi sangat ditentukan oleh kemauan peternak untuk mengadopsi teknologi inovatif yang dikenalkan dan dianjurkan oleh pemerintah. Selain itu, keputusan untuk mengadopsi teknologi baru banyak dipengaruhi oleh sifat dari teknologi itu sendiri (Soekartawi, 1998). Menurut Demita (2011), meskipun nilai kemanfaatan IB telah terbukti, namun upaya memaksimalkan inovasi teknologi IB masih terkendala oleh beberapa faktor seperti: terbatasnya pelayanan yang disediakan (SDM dan fasilitas), jumlah sapi akseptor yang relatif kecil, inseminator belum mampu menjadi agen pembaharu peternakan sapi potong, pola pemeliharaan sapi sebagian besar bersifat semi intensif, dan anggapan yang masih kuat di kalangan peternak bahwa perkawinan secara IB terasa memberatkan karena membutuhkan biaya cukup besar.

Kabupaten Sumbawa Barat (KSB) merupakan salah satu kabupaten di Provinsi NTB yang memiliki populasi sapi potong cukup besar. Salah satu wilayah di KSB yang jumlah sapinya cukup besar adalah Kecamatan Brang Rea yaitu sebanyak 4,571 ekor. Di kecamatan ini program IB telah diperkenalkan sejak 2008 dengan jumlah peternak sapi potong 510 orang. Guna mendukung program IB, pemerintah daerah KSB telah mengalokasikan sumber daya melalui pengadaan berbagai peralatan penting untuk pelayanan IB. Intervensi ini dilakukan sejalan dengan peningkatan infrastruktur ternak di daerah produktif dan perekrutan inseminator yang memberikan layanan IB untuk peternak sapi skala kecil. Upaya memperkenalkan dan mengintrodusir teknologi IB di wilayah KSB diharapkan mampu mendorong pengembangan sapi potong melalui peningkatan kinerja reproduksi sehingga pada gilirannya dapat meningkatkan produktivitas sapi.

Meskipun sudah diintrodusir selama 10 tahun serta sarana dan prasarana IB telah dilengkapi oleh pemerintah $\mathrm{KSB}$, namun kecepatan adopsi terhadap teknologi IB masih rendah yaitu kurang dari 40\% (Dinas Kelautan, Perikanan dan Peternakan KSB, 2016). Menurut Hastuti (2008), tingkat keberhasilan IB sangat dipengaruhi oleh empat faktor yang saling berhubungan yaitu pemilihan sapi akseptor, pengujian kualitas semen, akurasi deteksi birahi oleh peternak dan keterampilan inseminator. Namun demikian, di luar keempat faktor teknis tersebut, faktor psikologis utama yang menentukan tingkat keteradopsian suatu teknologi adalah karakterisitk peternak sapi yang akan mengadopsi menerapkan teknologi IB. Karakteristik peternak ialah bagian dari individu peternak yang mendasari perilaku peternak. Karakteristik peternak ini dapat berupa pengetahuan, sikap dan motivasi tentang teknologi IB. Menurut Mardikanto (1993), 
semakin tinggi tingkat pengetahuan peternak, semakin mudah inovasi baru teradopsi. Kurangnya pengetahuan di kalangan peternak menyebabkan rendahnya tingkat adopsi dan kemauan untuk mengimplementasikan inovasi baru.

Motivasi yang tinggi akan berpengaruh terhadap adopsi teknologi IB. Okkyla et al. (2013) menyatakan bahwa terdapat hubungan yang positif antara motivasi peternak dengan sikap dalam pemanfaatan teknologi IB. Untuk mengetahui secara tepat tingkat pengetahuan yang berhubungan dengan sikap dan motivasi peternak dalam upaya pengadopsian teknologi IB maka diperlukan suatu kajian lapangan. Oleh karena itu, penelitian ini dilaksanakan dengan tujuan untuk mendapatkan gambaran tentang hubungan antara tingkat pengetahuan, sikap dan motivasi peternak sapi terhadap adopsi teknologi IB di Kecamatan Brang Rea, Kabupaten Sumbawa Barat.

\section{MATERI DAN METODE}

Penelitian dilakukan mulai Agustus sampai Septembar 2018 di Kecamatan Brang Rea KSB, Provinsi NTB. Jenis penelitian ini adalah deskriptif korelatif dengan pendekatan cross sectional. Pengambilan data primer dilakukan melalui wawancara tatap muka dengan bantuan kuesioner yang disusun secara tersturktur. Sebanyak 84 responden dari sembilan desa di Kecamatan Brang Rea dipilih secara acak dari total 510 orang peternak tanpa memperhatikan jumlah kepemilikan dan strata umur sapi yang dipelihara. Data survey yang terkumpul diberi penilaian (scoring) pada lembar kuesioner. Total nilai dari komponen pengetahuan, sikap dan motivasi dikelompokkan menjadi 3 kategori: (1) tinggi/baik, (2) cukup/cukup baik, dan (3) kurang/kurang baik, dengan menggunakan interval (I) dan range (R). Range adalah total nilai tertinggi dikurangi total nilai terendah dan interval adalah range dibagi jumlah kategori.

Data dianalisis secara univariat untuk memperoleh prosentase responden berdasarkan umur, jenis kelamin, jenis pendidikan serta prosentase tingkat pengetahuan, sikap dan motivasi responden. Hubungan ketiga komponen pengetahuan, sikap dan motivasi dianalisis dengan analisa bivariat menggunakan metode Rho Spearman pada program SPSS 17.00 .

\section{HASILDAN PEMBAHASAN}

\section{Karakteristik Peternak}

Tabel 1 menyajikan statistik deskriptif dari sampel responden di Kecamatan Brang Rea $(n=84)$. Sebagian besar (94\%) peternak sapi potong berjenis kelamin laki-laki dengan kisaran umur tertinggi antara 41-50 tahun (35\%) dan terendah antara 20-30 tahun (15\%). Berdasarkan tingkat pendidikannya, sebagian besar $(45 \%)$ peternak sapi potong di wilayah penelitian telah menyelesaikan pendidikan dasar (SD), diikuti $22 \%$ pendidikan SMP dan $22 \%$ pendidikan SMA.

Tabel 1. Karakteristik sosio-demografi responden di Kecamatan Brang Rea, KSB $(\mathrm{n}=84)$

\begin{tabular}{llcc}
\hline Karakteristik & & Jumlah & $\%$ \\
\hline Umur (tahun) & $20-30$ & 13 & 15 \\
& $31-40$ & 26 & 31 \\
& $41-50$ & 29 & 35 \\
& $>50$ & 16 & 19 \\
\hline \multirow{2}{*}{ Jenis kelamin } & Laki-laki & 79 & 94 \\
& Perempuan & 5 & 6 \\
\hline Pendidikan & Tidak tamat SD & 3 & 4 \\
& Tamat SD & 38 & 45 \\
& Tamat SMP & 19 & 22 \\
& Tamat SMA & 21 & 25 \\
& Tamat D3/S1 & 3 & 4 \\
\hline
\end{tabular}

Keteranagan: $\mathrm{SD}=$ Sekolah Dasar, SMP = Sekolah Menengah Pertama, SMA = SekolahMenengah Atas, D3 = Diploma Tiga, S1 = Strata Satu 


\section{Sumber Informasi Teknologi IB}

Dalam kaitannya dengan informasi yang diperoleh peternak sapi potong tentang teknologi IB, sumber informasi terbesar diperoleh dari petugas penyuluh $(40,5 \%)$, kemudian berturutturut dari sesama peternak $(39,3 \%)$, sumbersumber lainnya (13\%), dari surat kabar $(4,8 \%)$, dan televisi $(2,4 \%)$ (Gambar 1).

\section{Tingkat Pengetahuan, Sikap dan Motivasi responden}

Tingkat pengetahuan, sikap dan motivasi responden dalam mengadopsi teknologi inseminasi buatan disajikan dalam Tabel 2.Data pada Tabel 2 menunjukkan bahwa 46,4\% tingkat pengetahuan responden termasuk kategori cukup sedangkan kategori kurang 23,8\%. Kurangnya pengetahuan responden tersebut dicerminkan dari tingginya prosentase responden yang tidak mengetahui waktu yang tepat kapan IB dilakukan (Gambar 2). Demikian pula prosentase pengetahuan reponden mengenai peralatan yang dipakai dalam pelaksanaan IB, $70 \%$ peternak sapi menyatakan tidak tahu (Gambar 3). Responden beranggapan bahwa alat-alat yang dipergunakan untuk IB hanya petugas yang perlu mengetahui. Rendahnya pendidikan responden kemungkinan merupakan penyebab utama dari kurangnya pengetahuan mereka terhadap kedua hal tersebut karena kebanyakan di antara mereka (45\%) hanya lulusan SD (Tabel 1).

Dilihat dari aspek sikap dalam mengadopsi teknologi IB, 51,2\% responden berada dalam kategori cukup baik dan 22,6\% dalam kategori kurang baik (Tabel 2). Responden dengan kategori kurang baik ini ditunjukkan dari sikap mereka yang tidak setuju untuk mengkandangkan ternaknya $(85,7 \%)$ dan tidak setuju memelihara ternak sapinya secara intensif (82\%) (Gambar 4).

Dalam hubungannya dengan aspek motivasi, sebagian besar $(51,2 \%)$ responden berkategori cukup dan $28,6 \%$ berkategori tinggi, hanya sebagian kecil $(20,2 \%)$ yang berkategori kurang (Tabel 2). Motivasi yang tinggi diindikasikan oleh tingginya jumlah responden yang ingin mendapatkan informasi tentang IB $(96,4 \%)$ dan menyatakan setuju apabila teknologi IB dapat meningkatkan kesejahteraan hidup peternak (65\%). Sebaliknya, hanya $25 \%$ responden yang motivasinya kurang sebagaimana dinyatakan oleh ketidakinginan mereka terlibat aktif dalam program IB (Gambar 5).

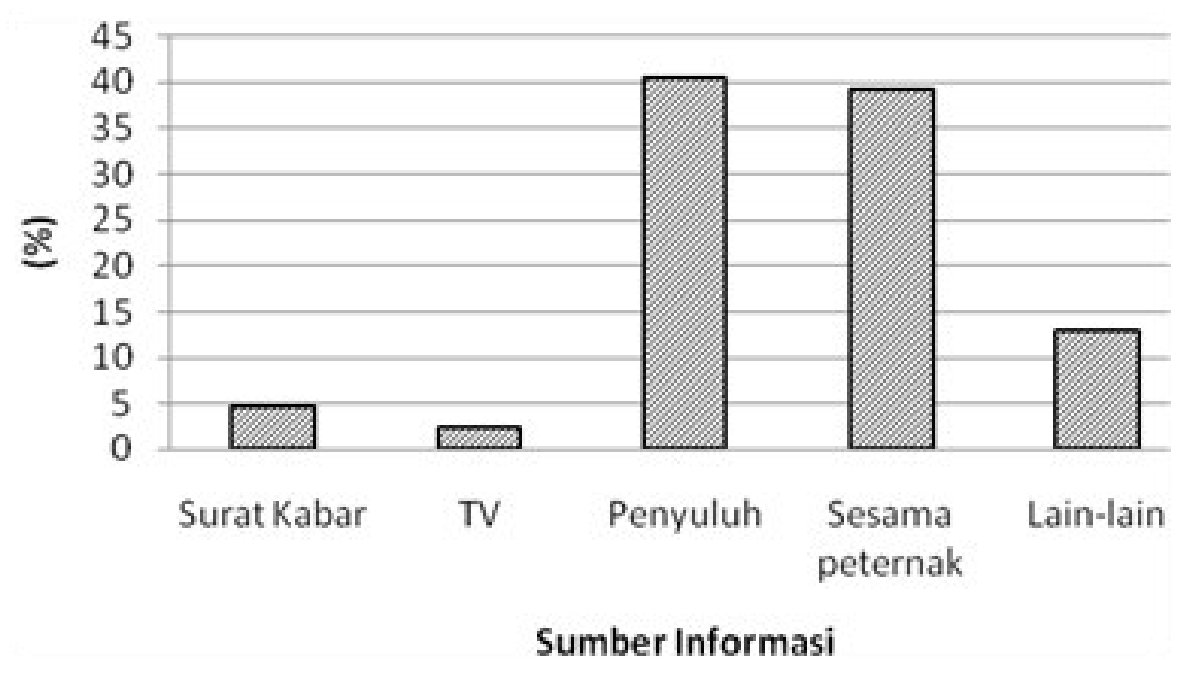

Gambar 1. Sumber-sumber informasi teknologi inseminasi buatan 
Tabel 2. Tingkat pengetahuan, sikap dan motivasi responden dalam mengadopsi teknologiinseminasi buatan di Kecamatan Brang Rea, KSB $(\mathrm{n}=84)$

\begin{tabular}{llccc}
\hline Kategori & & $\%$ & Interval (I) & Range (R) \\
\hline \multirow{2}{*}{ Pengetahuan } & Tinggi & 29,8 & $36-50$ & 15 \\
& Cukup & 46,4 & $22-35$ & $5-21$ \\
& Kurang & 23,8 & $49-70$ & 21 \\
\hline Sikap & Baik & 26,2 & $28-48$ & \\
& Cukup Baik & 51,2 & $7-27$ & 18 \\
& Kurang Baik & 22,6 & $42-54$ & \\
\hline Motivasi & Tinggi & 28,6 & $24-41$ & \\
& Cukup & 51,2 & $6-23$ & \\
& Kurang & 20,2 & & \\
& & &
\end{tabular}

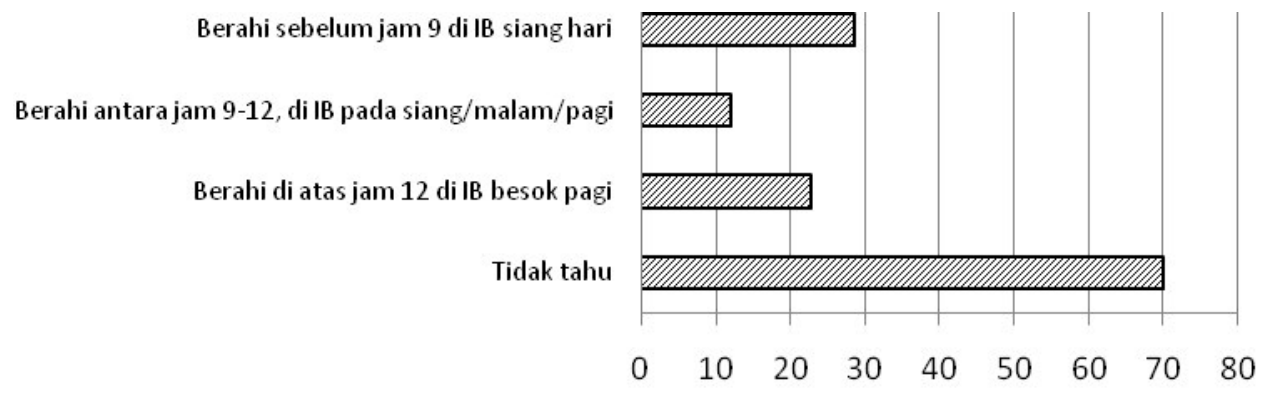

$(\%)$

Gambar 2. Pengetahuan responden mengenai waktu yang tepat melakukan inseminasi buatan

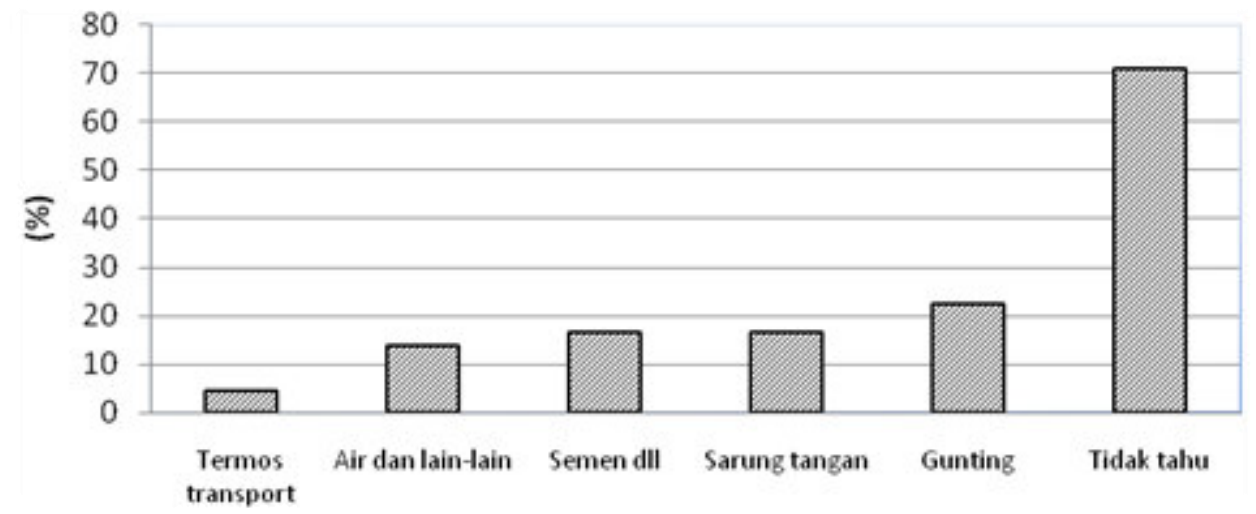

Gambar3. Peralatan yang digunakan dalam pelaksanaan inseminasi buatan 


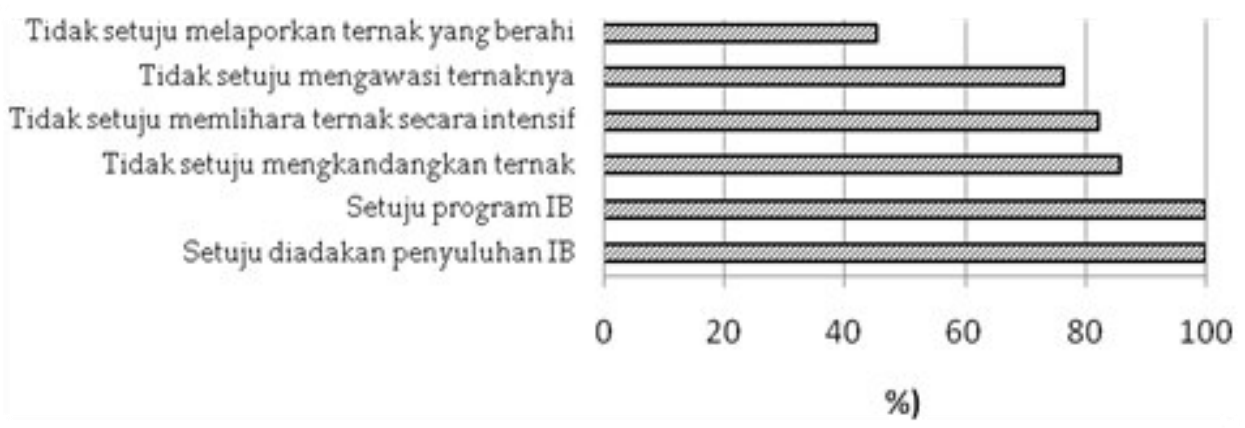

Gambar4. Sikap responden dalam mengadopsi teknologi inseminasi buatan

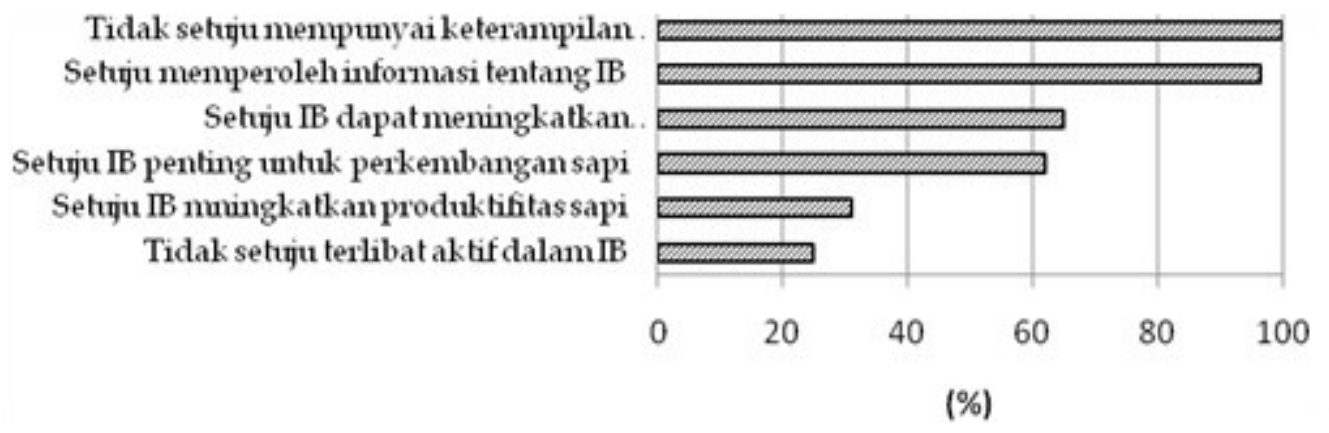

Gambar 5. Motivasi responden dalam mengadopsi teknologi inseminasi buatan

\section{Hubungan Antara Aspek Pengetahuan, Sikap, dan Motivasi}

Analisis empiris hubungan antara pengetahuan dengan sikap ditunjukkan dalam Tabel 3.Hubungan antara pengetahuan dengan kategori cukup dan sikap dengan kategori cukup baik didapati paling tinggi (42\%) sedangkan hubungan antara pengetahuan dengan kategori kurang dan sikap dengan kategori kurang baik adalah $21 \%$. Hal ini mengindikasikan bahwa dengan berbekal pengetahuan yang cukup disertai sikap yang cukup baik akan mampu mendukung program teknologi IB. Uji statistic Rho Spearman menunjukkan adanya hubungan yang tinggi $(\mathrm{P}<0,05)$ antara pengetahuan dengan sikap responden dalam mengadopsi teknologi IB dengan nilai koefesien korelasi (r) positip sebesar 0,85. Ini berarti pengetahuan mempunyai pengaruh positif terhadap sikap dan peningkatan pengetahuan responden akan diikuti oleh perubahan sikap sebesar $85 \%$. Tabel 4 menyajikan hubungan antara pengetahuan responden tentang adopsi teknologi IB dengan motivasi responden dalam mendukung program IB.

Hubungan antara pengetahuan dengan kategori cukup dan motivasi dengan kategori cukup menghasilkan nilai prosentase sebesar $44 \%$, sedangkan pengetahuan dengan kategori kurang dan motivasi dengan kategori kurang prosentasenya sebesar $19 \%$. Hal ini mengindikasikan bahwa dengan pengetahuan yang cukup tercermin motivasi responden yang cukup dalam mendukung program teknologi IB. Uji statistik Rho Spearman memperlihatkan hubungan yang signifikan $(\mathrm{P}<0,05)$ antara pengetahuan dengan sikap responden dalam mengadopsi teknologi IB dengan nilai $r=0,82$. Nilai $\mathrm{r}$ yang tinggi ini menyiratkan bahwa pengetahuan memberikan pengaruh positif terhadap motivasi dan peningkatan pengetahuan responden akan diikuti oleh perubahan motivasi sebesar $82 \%$.

Berdasarkan Tabel 5, hubungan antara sikap dengan kategori cukup baik dan motivasi dengan kategori cukup didapati paling tinggi yaitu $46 \%$ dan $22 \%$ menunjukkan sikap dengan kategori kurang baik dan motivasi dengan kategori kurang. Uji statistik dengan Rho Spearman menunjukkan bahwa hubungan antara kedua aspek tersebut adalah signifikan $(\mathrm{P}<0,05)$ dengan nilai $r=0,85$. Nilai ini menunjukkan bahwa sikap mempunyai pengaruh positif terhadap motivasi dan peningkatan sikap responden akan diikuti oleh perubahan motivasi sebesar $80,5 \%$. 
Tabel 3. Hubungan antara aspek pengetahuan dan sikap

\begin{tabular}{cccccc}
\hline \multirow{2}{*}{ Kategori } & & \multicolumn{5}{c}{ Sikap (\%) } \\
\cline { 3 - 6 } & & Baik & Cukup Baik & Kurang Baik & Jumlah \\
\hline \multirow{3}{*}{ Pengetahuan } & Tinggi & 24 & 6 & 0 & 30 \\
& Cukup & 2 & 42 & 2 & 46 \\
\hline & Kurang & 0 & 3 & 21 & 24 \\
\hline
\end{tabular}

Tabel 4. Hubungan antara aspek pengetahuan dengan motivasi

\begin{tabular}{cccccc}
\hline \multirow{2}{*}{ Kategori } & \multicolumn{4}{c}{ Motivasi (\%) } \\
\cline { 3 - 6 } & & Tinggi & Cukup & Kurang & Jumlah \\
\hline \multirow{3}{*}{ Pengetahuan } & Tinggi & 27 & 2 & 0 & 29 \\
& Cukup & 1 & 44 & 2 & 47 \\
& Kurang & 0 & 5 & 21 & 19 \\
\hline
\end{tabular}

Tabel 5. Hubunganantara aspek sikap dengan motivasi

\begin{tabular}{llcccc}
\hline \multirow{2}{*}{} & Kategori & \multicolumn{4}{c}{ Motivasi (\%) } \\
\cline { 3 - 6 } & & Tinggi & Cukup & Kurang & Jumlah \\
\hline \multirow{3}{*}{ Sikap } & Baik & 24 & 2 & 0 & 26 \\
& Cukup Baik & 4 & 46 & 0 & 50 \\
& Kurang Baik & 0 & 2 & 22 & 24 \\
\hline
\end{tabular}

Hasil penelitian sekarang mencatat jumlah responden laki-laki sebanyak $94 \%$, jumlah ini lebih tinggi daripada yang dilaporkan oleh Ingabire et al. (2018) yaitu 55,6\%. Jumlah responden yang tinggi tersebut menyiratkan bahwa lebih banyak peternak laki-laki yang berpartisipasi dalam usaha produksi sapi potong daripada yang perempuan.

Sebanyak 35\% peternak sapi potong di wilayah Brang Rea berada dalam usia produktif (41-50 tahun) sehingga mampu meningkatkan produksi sapi untuk meningkatkan kesejahteraan mereka. Usia peternak ini lebih tinggi daripada umur peternak yang dilaporkan oleh Ingabire $e t$ al. (2018) di mana ranking tertinggi umur peternak baik yang memanfaatkan dan tanpa memanfaatkan teknologi IB adalah antara 20-40 tahun. Peternak sapi yang berada dalam umur produktif dapat mengadopsi dan menggunakan teknologi baru lebih efisien dibandingkan peternak yang lebih tua dan dengan demikian berhasil mempertinggi tingkat produktivitas (Quddus, 2013).

Jumlah peternak sapi yang menamatkan SD $(45 \%)$ dalam penelitian ini sama seperti yang dicatat oleh Quddus (2017) yaitu 45,7\%. Sebaliknya, Ingabire et al. (2018) mencatat jumlah peternak sapi yang menyelesaikan SD lebih tinggi yaitu sebanyak $72 \%$. Pencapaian pendidikan tetap menjadi atribut atau ciri yang mendasari dalam meningkatkan laju adopsi teknologi (Ingabire et al., 2018).

Peternak sapi potong di KSB memperoleh informasi tentang teknologi IB adalah dari petugas penyuluh peternakan. Informasi terbanyak yang diberikan oleh penyuluh ini sesuai dengan yang dikemukakan oleh Purba (2013) bahwa, seorang penyuluh sebagai agen perubahan bertugas menyebarkan inovasi baru kepada masyarakat. Kemudian dipertegas oleh 
Assegaf (2007) yang menyatakan bahwa, intensitas penyuluhan yang diterima oleh peternak dari penyuluh lapangan merupakan salah satu faktor yang mempengaruhi kecepatan adopsi suatu inovasi.

Tingkat pengetahuan responden dalam upaya mengadopsi teknologi IB masih kurang dari $50 \%$. Kurangnya pengetahuan responden tersebut dicerminkan dari tingginya jumlah responden $(70 \%)$ yang tidak mengetahui waktu yang tepat untuk mengawinkan ternak sapinya secara IB (Gambar 2). Untuk pengetahuan tentang peralatan IB, peternak responden beranggapan bahwa alat-alat yang dipergunakan untuk IB cukup petugas IB saja yang perlu mengetahuinya. Rendahnya pendidikan responden kemungkinan merupakan penyebab utama dari kurangnya pengetahuan mereka terhadap kedua hal tadi karena kebanyakan mereka (45\%) hanya lulusan SD (Tabel 1).

Dalam kaitannya dengan sikap responden dalam mengadopsi teknologi IB, lebih dari $80 \%$ peternak sapi tidak setuju mengkandangkan ternaknya dan memelihara sapinya secara intensif. Alasan penolakan mereka dikarenakan dengan mengkandangkan dan memelihara sapi secara intensif maka lebih banyak waktu yang dibutuhkan. Peternak menganggap beternak sapi merupakan kegiatan sampingan dan pekerjaan utamanya sebagai petani di mana sebagian besar waktunya dihabiskan untuk mengurus sawah dan bercocok tanam. Dengan memelihara sapi secara intensif dalam kandang maka dikhawatirkan perhatian terhadap ternak sapi menjadi kurang fokus.

Dalam penelitian sekarang hubungan antara pengetahuan dan sikap, pengetahuan dan moivasi, sikap dan motivasi didapati sangat tinggi dengan nilai koefisien korelasi (r) masing-masing $r=0,85, \quad r=0,82$ dan $r=0,85$. Adanya korelasi yang tinggi antara pengetahuan dan sikap adalah sejalan dengan pernyataan Miftahudin \& Kartinah (2008) bahwa, semakin baik pengetahuan responden maka semakin baik pula sikap responden. Menurut Notoatmodjo (2007), penentuan sikap dipengaruhi oleh pengetahuan, taraf berfikir, keyakinan dan emosi. Pengetahuan akan merangsang sesorang atau individu untuk berfikir dan berusaha agar dapat menciptakan keseimbamgan. Untuk mempertahankan sikap yang baik selain melalui penyuluhan yang intensif, juga diperlukan pembinaan secara berkala baik secara langsung ke peternak maupun diskusi kelompok. Melalui diskusi ini terjadi interaksi antaranggota kelompok untuk saling berbagi pengalaman sehingga menambah luas wawasan peternak dalam pemeliharaan ternak sapi yang baik.

Tingginya korelasi antara pengetahuan dan motivasi didukung oleh Abdurrahman dan Muhiddin (2007) yang menyatakan bahwa meningkatnya pengetahuan responden akan diiringi pula dengan meningkatnya motivasi. Dengan pengetahuan yang tinggi, maka peternak lebih mudah mengadopsi inovasi baru. Selanjutnya tingginya korelasi antara sikap dan motivasi mengindikasikan bahwa meningkatnya motivasi responden terhadap pemanfaatan teknologi IB, akan meningkatkan sikap diri responden itu sendiri. Sikap seseorang ditentukan oleh kepentingan yang dirasakan responden, apabila responden merasa bahwa IB dapat meningkatkan produktivitas usahanya, maka secara tidak langsung responden akan merubah sikap beternaknya menjadi lebih baik. Hal ini sesuai dengan pendapat Danim (2004) yang menyatakan bahwa sikap seseorang sangat ditentukan oleh kepentingan-kepentingan yang dirasakan. Semakin responden merasa memiliki kepentingan terhadap teknologi IB maka sikapnya pun menjadi semakin baik.

\section{KESIMPULAN}

Tingkat pengetahuan responden sebagian besar cukup baik dan tercermin pada sikap dan motivasi mereka dalam upaya adopsi teknologi IB. Upaya adopsi teknologi IB dapat dilakukan dengan pemilihan calon sapi yang baik, deteksi berahi yang tepat, keterampilan petugas inseminator yang bagus, sarana dan prasarana yang memadai dan pemahaman peternak dalam pemeliharaan ternak sapi. Terdapat hubungan yang signifikan, positip dan tinggi antara pengetahuan, sikap dan motivasi responden dalam adopsi teknologi IB.

\section{DAFTAR PUSTAKA}

Abdurrahman, M., \& S.A. Muhiddin. 2007. Analisis korelasi, regresi dan jalur dalam penelitian. Pustaka Setia. Bandung.

Assegaf, C.C. 2007. Faktor-faktor yang mempengaruhi kecepatan adopsi teknologi biogas oleh peternak sapi potong di Desa Timbuseng Kecamatan Polangbangkang Utara Kabupaten Takalar. Skripsi. Fakultas Peternakan Universitas Hasanudin. Makassar. 
Danim, S. 2004. Motivasi kepemimpinan dan efektivitas kelompok. Rineka Cipta. Jakarta.

Demita, N. 2011. Adopsi inovasi inseminasi buatan pada peternak sapi potong di Kecamatan Kuranji. Skripsi. Fakultas Peternakan Universitas Andalas. Padang.

Dinas Kelautan, Perikanan dan Peternakan Kabupaten Sumbawa Barat. 2016

Eklundh, C. 2013. The use of artificial insemination in dairy farms in urban/periurban Kampala, Uganda - A study of knowledge, attitude and practices. Swedish University of Agricultural Sciences [Online] Available: http://stud.epsilon.slu.se/5326/7/eklund_c _130227.pdf

Foote, R.H. 2002. The history of artificial insemination: selected notes and notables. American Society of Animal Science, Cornell University, Ithaca.

Hastuti, D. 2008. Tingkat keberhasilan inseminasi buatan sapi potong ditinjau dari angka konsepsi dan service per conception. Fakultas Pertanian Universitas Wahid Hasyim. Mediagro. 4:12-20.

Ingabire, M.C., L. Yonggong, J.C. Pesha, \& A. Hardi. 2018. Factors affecting adoption of artificial insemination technology by small dairy farmers in Rwanda: A case of Rwamagana District. Journal of Economics and Sustainable Development 9:46-53.

Mardikanto, T. 1993. Penyuluhan Pembangunan Pertanian. Universitas Negeri Sebelas Maret. Surakarta Press. Surakarta.

Ma'sum, K., M.A. Yusran, \& M. Rangkuti, M. 1993. Proseding pertemuan ilmiah hasil penelitian dan pengembangan sapi madura. Sub Balai Penelitian Ternak Grati. Sumenep. Madura. Jawa Timur.

Miftahudin, A.A., \& Kartinah. 2008. Hubungan pengetahuan tentang flu burung dengan sikap masyarakat yang memelihara unggas di Wilayah Mojogedang. Jurnal Ilmu Keperawatan 1:157-162.

Notoatmodjo, S. 2003. Pendidikan dan prilaku kesehatan. PT Rineka Cipta. Jakarta.
Okkyla, S., Isbandi, \& D. Samsudewa. 2013. Hubungan motivasi dengan prilaku dalam pemanfaatan teknologi inseminasi buatan pada peternak anggota kelompok tani ternak sapi perah. Fakultas Peternakan dan Pertanian Universitas Diponegoro. Semarang. Animal Agricultural Journal 2:1-7.

Pateda, S.Y. 2010. Tingkat adopsi petani terhadap teknologi inseminasi buatan pada sapi di Kecamatan Paguyaman. Fakultas Ilmu-ilmu Pertanian. Univerrsitas Negeri Gorontalo. Saintek 5:1-6.

Purba, E.S.F. 2013. Komunikasi penyuluhan dan tingkat adopsi inovasi. Studi korelasi tentang pengaruh komunikasi penyuluhan perkoperasian Indonesia oleh Dinas Koperasi dan UKM Provinsi Sumatra Utara terhadap tingkat adopsi inovasi koperasi pada masyarakat Kelurahan Pangkalan Mansur Medan). Jurnal Ilmu Komunikasi Flow 2(7). https://jurnal.usu. ac.id/index.php/flow/article/view/11492/ 4947

Quddus, M.A. 2013. Performance and perceptions of adoption of crossbred cattle by smallholder in Bangladesh. International Journal of Agricultural Policy and Research 5:63-69.

Quddus, M.A. 2017. Adoption of Dairy farming technologies by small farm holders: practices and constraints. Bangladesh Journal of Animal Science 41:124-135.

Shehu, M.B., M.D. Kezi, \& T.D. Bidoli. 2011. Challenges to farmers' participation in artificial insemination (AI) biotechnology in Nigeria: An overview. Journal of Agricultural Extension 14:2.

Soekartawi. 1998. Prinsip dasar komunikasi pertanian. UI Press. Jakarta. 